contains an elaborate discussion of the petrochemistry of various well-known petrographical provinces as well as very valuable chapters on geochemistry and crystal chemistry in relation to the composition and mode of formation of igneous rocks and an interesting discussion on the problem of rock classification and differentiation of magma. It would be rather difficult to explain here in detail his graphical method of representation of rock analyses which, in its essence, is a complete geometrization of chemistry. This method, in brief, consists in the recalculation of the chemical analysis as a number of coefficients expressing the relative amounts of chemical elements, and then the ten coefficients thus obtained are plotted on an opened-up rectangular tetrahedron. Each analysis is represented by two vectors the position, length and inclination of which characterize the composition of the rock in question. By means of these diagrams he is able to survey large assemblages of rocks and also to compare various assemblages and discuss the problems of petrogenesis. Whether this method is really more efficient for coping with these problems than the previously devised schemes of Osann, Niggli, Wolff and others, can only be tested by an actual trial.

In his latest paper (Bull. Acad. Sci. URSS, Ser. Geol., No. 5, 12; 1944) Zavaritzky returns to the discussion of the equilibrium diagrams as applied to systems composed of a silicate melt and a volatile constituent. Although only an ideal case is discussed, his elaborate analysis of the processes which are liable to occur in this system through changes in concentration, temperature or pressure has an important bearing on the genesis of pegmatites and hydrothermal veins.

In conclusion, one can truly say that Zavaritzky has really made very important contributions to the progress of petrology and especially to the problems of petrogenesis and ore genesis, and it is only because the Russian language is not better known among soientific workers of other countries that his work has not been fully appreciated. It is true that many of his works have been abstracted in the Mineralogical Abstracts published by the Mineralogical Society, but no abstract, however full, can adequately represent the original. Adherence to facts and methods of exact observation are the main characteristics of Zavaritzky's work, and in his own words : "I consider that the fundamental object of science is the acquisition of the knowledge of new facts about real things and a precise statement of such facts and not agreement with such or such hypothesis, postulate, opinion or idea".

\section{GLACIAL GEOLOGY IN HOLLAND DURING THE WAR}

\section{BY D. DE WAARD}

Mineralogical Geological Institute, University of Utrecht

$\mathrm{D}$ URING the War, Dutch geological students were unable to undertake much of the field-work usually done in foreign countries. Most of them carried out research on the carboniferous and cretaceous beds in the south of the Netherlands, or the tertiary and younger formations in the rest of the Netherlands. The following is a brief summary of progress made in geological research on the glacial Pleistocene in the Netherlands during the War.
For some decades, it was a well-known fact that, though all research pointed to only one glaciation having covered a part of the Netherlands especially during the Riss glaciation, yet remarkable differences are found in the kinds of sedimentary erratics in the boulder clay from different localities. These differences have been ascribed to variations in the direction of the glacial stream within the Baltic Sea area, whereby East and West Baltic erratic associations appear near each other in the boulder clay.

Besides these, great differences have recently been found in the proportions of recognizable crystalline erratic rocks in the north-east Netherlands. Usually the associations of the recognizable crystalline erratics contain only about 20 per cent East Baltic stones, consisting of Rapakivi granites from the Alands Isles and southern Finland, and other kinds of stones from this area. This percentage proved to be typical of the deposits of the Riss glaciation. So it was very interesting to find in the north-east Netherlands an association with a much higher percentage of East Baltic rocks agreeing with the glacial deposits of the older Mindel glaciation in northern Germany. Some Dutch geologists have suggested as an explanation of these phenomena the existence of an older glaciation in this part of the Netherlands, though no other indications of a second glaciation have been found.

Further, some forty years ago, a theory of more than one ice-cover of a part of the Netherlands was based on the presence of different coloured boulder clays. This theory was rejected long ago, for the colour differences proved to be caused by normal weathering of the boulder clay. As, however, these arguments may be partly true, this theory should have further consideration.

To summarize, though only one glaciation has covered a part of the Netherlands, there are remarkable qualitative differences in the sedimentary erratics, quantitative differences in the recognizable crystalline erratics and-in addition to those caused by weathering-differences in the colour of the boulder clay, mainly found in the northern and north. eastern parts of the Netherlands.

More or less by accident, I found an explanation of these phenomena in the sea bottom of the former Zuyder Zee. Surveying the glacial deposits in the part of the Zuyder Zee reclaimed since 1940-the so-called north-eastern polder-between the former Isle of Urk and the old west coast near Vollenhove, I discovered several well-separated blocks of a typical boulder clay in the normal boulder clay. These blocks may be small or large, usually some 10-20 yards in diameter, mostly with an irregular outline and some. times twenty within a square mile. They lie in the surrounding boulder clay, partly or wholly covered by it.

In contrast to the normal surrounding boulder clay, which in the unweathered condition is dark grey or nearly black and may be weathered to a rusty brown or even bluish-grey, the boulder clay of these separated blocks has a carmine or hæmetitic colour. None of the colours of the normal boulder clay in the weathering series approaches this carmine reddish colour.

Besides the colour differences, the boulder clay of the separated blocks differs from the surrounding boulder clay in a great many ways. For example, it contains mostly sedimentary erratics from the East Baltic area, not found in normal boulder clay; it has a high percentage of Rapakivi granites and other recognizable East Baltic crystalline erratics, while 
the surrounding boulder clay has a normal low percentage; there are great differences in the percentages of lime and soluble iron, and also differences in the sedimentary petrology, in particular the percentage of dark minerals and the higher percentage of amphiboles, and the differences in the grain-size.

These differences indicate that these blocks of boulder clay have no connexion with the normal surrounding boulder clay. They must therefore have another origin. In view of the shape and the position in the normal boulder clay, it is clear that these are lenses or floes, composed of a different sort of boulder clay from the normal. It is probable that these floes are parts of another glacial deposit torn loose, embedded in the ground moraine and transported by the ice-cover during the Riss glaciation.

I have tried to find out from which glaciation these floes may have been formed. Indications of their origin may be the content of erratics. Both the east Baltic sedimentary rocks and the high-percentage Rapakivi rocks indicate a Mindel age. They resemble the autochthonic glacial deposits of the Mindel glaciation in the north of Germany.

In addition to the glacial areas on the bottom of the north-east of the former Zuyder Zee, I found these boulder clay floes in several different parts, about eighty altogether, of the north and east Netherlands. I should expect to find these floes in the adjoining Riss deposits in the north-east of Germany too. Their presence in the normal Riss deposits finally explains the abnormal east Baltic associations of erratics and the unusual colour differences of the boulder clay.

A detailed report on geological aspects of the existence, contents and spread of these boulder clay floes in the Netherlands will be published shortly.

\section{BOWLING-GREENS AND BOWLS}

\section{By J. H. COLE and DR. W. LAWRENCE BALLS, F.R.S.}

$I^{\mathbb{N}}$ Egypt, South Africa, and part of the United States, the bowling-greens have to be made with species of Cynodon (crested dogs-tail) grass, in order that they may stand up to summer heat. This grass, known to us in two or three species and many varieties, has a habit of one-sided growth, which imparts a one-way 'nap' to the playing surface, not only on bowling-greens but on putting-greens also. Both bowlers and golfers in these countries are used to seeing the ball run as if the whole surface of the green were sloping, though it may be dead level. The intensity of the effect varies from one strain to another: the Indian 'dhob' is the worst we have met; the less coarse Egyptian 'negeel' and the quarterscale $C$. transvaalensis (called 'Uganda' in Egypt) both behave alike, though the latter is so much finer in texture as a lawn. On the other hand, a strain which is nap-free, known as 'Royal Cape', was isolated by Dr. Murray near Cape Town. We have checked this (with Mr. R. P. Black) in propagation plots at the Gezira Sporting Club in Cairo; it is, however, quite exceptional, and not easy to establish in Egypt.

The direction in which the nap points, and its intensity, can be measured in several ways. The earliest we used, and slowest but most direct, is to roll a ball of any kind down a chute towards all points of the compass in succession, and plot a polar diagram of the distances reached in each direction. The quickest, and most useful practically, since it will deal with a single square foot in each reading, is to oscillate a smooth six-inch disk of wood on the grass surface, noting the direction in which it moves, and how quickly; this can be done easily and accurately by using a light tripod about four feet high with an operating handle at the top, and a light duraluminium tube with universal joints connecting the disk to the handle at the top, without introducing any lateral displacement couple. Even now we are in doubt as to the components of the nap; it is not entirely superficial, since a green may show more nap after mowing than it had when uncut; we have even found traces of nap in a different direction under the predominant one. It would seem that the root-stoeks of the grass build up a 'geological' structure recording the history of the nap.

Our earliest observations at the Gezira Sporting Club showed that the nap in 1930, under the regime of grass-control then employed, had a general trend to the north-west. Under our present regime of heavy manuring (sulphate of ammonia) and hard cutting, it points mostly west of south. The startingpoint, with zero nap, is a lawn which has been 'skinned' of its grass-cover, and allowed to regenerate from the root-stocks. Six months later we have seen a slight westward nap in the late winter, a south. ward nap by the late summer, and finally a settling. down to south-west. But the settling-down is incomplete, and lawns which have not been skinned for years will still show changes over a swing of some seventy degrees, under the same regime, as the seasons change. Obviously the cause of nap is complex, but it would seem that its direction is determined primarily by water-strain, the precise development of the reaction thereto being determined by the balanee of soil-moisture, manuring, and weather conditions. It need scarcely be added that the system of mowing is so arranged as to eliminate that possible cause completely.

Very strange bowl-tracks can be obtained when playing on such nappy lawns with the wrong kind of bowl, or when using the testing-chute. An English 'standard bowl' may take two feet of bias against the nap, but six feet with the nap, if the chute is set at right angles to the nap-direction. If set to bowl up and down the nap-direction, it may give even bias in both hands, but run several yards farther with the nap than against it. The effect on the muscular effort of the bowler is the same as if the green-surface were on the slope.

Bowls of modified shape give still stranger results. A flat track only half an inch in width, cut on the tread of a normal bowl, will make it entirely independent of the gravitational bias given it by its maker. Like a skater rocking from inside to outside edge, and back again, it will take a sigmoid course as the nap along its track changes direction locally. On a green with uniform and strong nap it is almost impossible to guess from its course which bias had been given; the nap takes complete control. As a limit case of this, instead of the cylindrical track, we can make a frustum of a cone, wider than it is high, when lying on its side; the path of this at low speed, or on a napless green, must be an arc of a circle, there being no gravitational bias; but if bowled fast on a nappy green against the nap it will turn a somersault.

It was noticed that bowls constructed by different makers were affected in varying degree. One Aus. 